\section{Beta Distribution for Estimating Risk Associated Time Schedule of Hydropower Projects in Nepal}

\author{
Kiran Kumar Shrestha' and Rabindra Kayastha ${ }^{2 *}$
}

Submitted: 18 August 2021; Accepted: 13 November 2021

Published online: 5 December 2021

DOI: https://doi.org/10.3/26/njs.v5il.4I 230

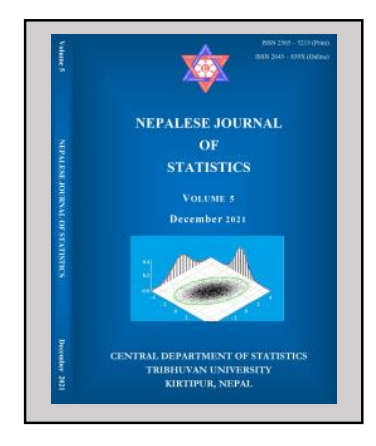

\begin{abstract}
Background: Risk is associated with every kind of project work whether it is related to engineering construction project, software development project, financial transaction process or business process. There isn't any project which is free of risks. It is inherent in all types of projects. Observing risk associated with a project can help in successful completion of projects in expected time and expected cost with good assurance of quality. This article is concerned with quantitative analysis of risks coined with hydropower construction project in Nepal.
\end{abstract}

Objective: The main objective of this paper is (a) to identify different activities involved in hydropower construction projects (b) to estimate risk associated time schedule of the identified project activities.

Materials and Methods: Data required for the fulfillment of the objective are obtained by interview and discussion with executives of "Shiva Shree Hydropower Limited" and by using project schedule charts of projects won by the company. In this article quantitative analysis of schedule risk of hydropower project is studied by simulation method.

Results: Different activities involved in hydropower construction project are identified. Also, risk associated with time schedule of project are observed quantitatively by simulation using beta-PERT distribution.

Conclusion: Estimation of time schedule associated with project activities is more realistic when it is analyzed by using beta-PERT distribution compared to other statistical distributions.

Keywords: Beta-Pert distribution, Monte Carlo simulation, quantitative risk analysis, random numbers, risk assessment, risk management.

Address correspondence to the author: Department of Mathematics, School of Science, Kathmandu University, Dhulikhel, Nepal', 2. E-mail: kiran.shrestha@ku.edu.np';

rkayastha@ku.edu.np ${ }^{2 *}$ (corresponding author email) 


\section{INTRODUCTION}

A risk management project is the method of describing and examining risks and determining proper ways of action minimizing these risks and achieving their own business goals. The essential and necessary steps about the risk management project should be included and dealt with risks for the proper operation of a project. A project is a sequence of tasks that is carried to attain some output. If a project, whether it is a construction project or research project or software project, is completed in time and on a budget as scheduled, then it can be considered as a success. All projects do not end up with a success. A number of influencing factors cause hindering of project success. There is a significant relationship between the risk management approach and project's success (Voetsch, 2004). Due to the nature of projects based on the well-known survey of the Chaos Report (Ismaili, 1995), the results in 1995 shows that $52.7 \%$ of the projects' cost over $189 \%$ of its original estimates with only $9 \%$ of large organizations' projects being delivered on-time and on-budget while a minimum improvement on the figures was reported in 2009 where $44 \%$ of the projects' cost overrun and/or completed late. Also, the KPMG International survey of 600 organizations across 22 countries indicated that $86 \%$ of the respondents reported a $25 \%$ loss of their targeted benefits across their project portfolios due to poor project management (Kolk, Kourula, Pisani, \& Westermann-Behaylo, 2019).

Crawford (2014) found that nearly half of organizational projects are at risk at any given time regardless of the size of the organization. It is evident that there are a lot of underlying reasons behind all these failures in projects that lead many practitioners as well as researchers to take a step forward to diagnose and understand the root cause of these failures. (Flyvbjerg, 2018) identified insufficient consideration about risk and the lack of accountability in the project decisionmaking process to be the main causes of the mega projects' paradox. Effective risk analysis helps the developer to decide whether the project is safe or not for investment. (Gurung, 2020). In Nepal, hydropower plants are becoming nowadays an attractive alternative source of energy and both governments and private investors are highly inclined towards generation of hydroelectricity. Government of Nepal is not only taking step in construction of mega-hydropower projects in Nepal but it is currently encouraging international organizations and domestic private sectors to invest in hydro electricity generation, through concession agreements and different type of contracts while guaranteeing the purchase of their output.

Nepal has an enormous potential for generating electric energy from its water resources. Due to the availability of large number of snow fed and monsoon fed rivers in Nepal, there is a large potentiality for hydropower development. In Nepal, there are generally running Run-off-River type (ROR), Storage type, and Peaking Run-off-River type (PROR) hydropower projects. There is basically four primary river system in Nepal: these are (i) the Mahakali, (ii) the Karnali, (iii) the Gandaki, and (iv) the Koshi systems. These systems can deal with a theoretical generation of 83,000 MW, and economically feasible likely to 42,000 MW. (Shrestha, 2018). Nepal's immense hydropower potential needs to exploit in broadening the market that is developing in domestic 
and regional areas. (Panthi, 2007). In spite of having such huge potential, Nepal produces only 847 MW from hydro power resources, and is only $2 \%$ of economically feasible potential (Firoj Alam, 2017). Besides of this Tripathi and Shrestha (2017) disclosed that risk assessment of boot hydropower projects in Nepal using fuzzy logic approach gave investors a more rational basis on which to make decisions and it could prevent cost and schedule overruns and indicators of project problems or potential difficulties (Tripathi \& Shrestha, 2017). Due to Nepal's strategic location between two giant economics China and India, Nepal has a competitive edge in producing and selling hydroelectricity. Power shortages in the region continue to constrain economic development. The domestic as well as regional market for the electricity is vast and rapidly growing. Being a mountainous country, consisting mainly of a large portion of Himalayas with huge rise and fall providing excellent head in short span, there are tremendous resources for the generation of electricity. Hydropower development in Nepal is happening at a very low pace due to various challenges/risks such as lack of investment, political instability, human resource constraints and lack of suitable plans and policies.

\section{MATERIALS AND METHODS}

In fact, different forms of risk come with different forms of strategic activities. Some common forms of risks associated with project management are - socio-economic risks, planning and designing risks, environmental risks, right-of-way acquisition, permitting requirements, third party agreements, technological risks, procurement risks, etc. In economic and business activities different types of risks involved are inflation risk, interest rate risk, currency risk, etc. The occurrence of risk is not deterministic, it is alway uncertain. Risk analysis uses concepts of probability to model such uncertainties affecting project cost and schedule. Risk analysis consists of two parts:

- $\quad$ Risk assessment - It includes risk identification, risk evaluation and risk prioritization.

- Risk management - It includes risk planning, risk mitigation and risk monitoring. It is the process of evaluating measures to mitigate cost and schedule risks by using information obtained from risk assessment. It involves taking cost-effective actions to reduce risks and to realize opportunities.

Qualitative risk analysis addresses individual risks in detail. It assesses the discrete probability of occurrence of different risks in discrete form and considers impact on objective if it occurs. This type of analysis helps in prioritization of individual risks for subsequent treatments. Qualitative risk analysis helps to create risk register and leads to quantitative risk analysis. Quantitative risk analysis is the practice of creating a mathematical model of a project or process that explicitly includes decision variables or parameters that we can control as well as uncontrollable variables or uncertain parameters. Such a model can help decision makers and policy makers to understand the impact of uncertainty and the consequence of different decisions. The obvious way to learn how to deal with uncertainty is to perform an experiment and generate data. But often, it is too dangerous or too costly or time consuming to perform such experiment in the study of risk related procedure. So we resort to a model which can be simulated to observe 
what happens in the real world and perform such hypothetical experiment repeatedly. In such simulation experiments uncertainties are introduced with statistical methods.

There are different techniques of simulation. The simplest and most common technique of simulation is Monte Carlo simulation. Monte Carlo simulation coins the terms 'random variable' and 'probability distribution' to measure severity of different risk factors. In Statistics random variables are considered as functions that describe probability distribution. The specification of random variables not only helps to describe the probability distribution of different uncertain events associated with risk factors but it also helps in generation of random numbers that are necessary to simulate them for quantitative risk analysis. Some common probability distributions that are used in simulation procedure of quantitative risk method are: (a) Uniform distribution (b) Poisson distribution (c) Normal distribution (d) Beta distribution, (e) triangular distribution, etc. Beta distribution is the most efficient and common distribution used to describe different risk related factors of project management task. Standard beta distribution can be implemented only within domain of 0 and $\mathrm{I}$. On extending these bounds to two finite non-zero values 'a' and 'b' a new form of beta distribution called generalized beta distribution is formed. In generalised beta distribution 'a' and 'b' represent lower and upper bounds of domain of the distribution. If $\mathrm{X}$ is a random variable having generalized beta distribution, then it is denoted as $X \sim$ betagen $(a, b, \alpha, \beta)$. Its probability density function is given by:

$$
f(x)=\frac{1}{B(\alpha, \beta)} \frac{(x-a)^{\alpha-1}(b-x)^{\beta-1}}{(b-a)^{\alpha+\beta-1}}
$$

Here $\alpha$ and $\beta$ are called shape parameters and 'a' is lower bound and 'b' is upper bound of the function. The mean and variance of of betagen $(a, b, \alpha, \beta)$ distribution are given by (Davis, 2006)

$$
\begin{gathered}
E(X)=a+(b-a) \times \frac{\alpha}{\alpha+\beta} \\
V(X)=(b-a)^{2} \times \frac{\alpha \beta}{(\alpha+\beta)^{2}(\alpha+\beta+1)}
\end{gathered}
$$

It is to be noted that if $X \sim \operatorname{betagen}(a, b, \alpha, \beta)$ then

$$
\frac{(X-a)}{(b-a)} \sim \operatorname{bet} a(\alpha, \beta)
$$

For simulation of project activities a special variant of generalized beta distribution known as beta-PERT distribution (commonly PERT distribution) is used. The PERT-distribution takes three positive values as parameters and they are:

- optimistic (minimum) value, denoted as $a$

- $\quad$ pessimistic (maximum) value, denoted as $b$

- most likely value, denoted as $m$

In this regard generalised beta distribution taking four parameters is modified into another form of beta distribution that takes three parameters to associate schedule risks associated with different project activities. Beta-PERT distribution is denoted as $X \sim \operatorname{betaPERT}(a, m, b)$. 
A constant, $\lambda$ is used as bridge factor between 'betagen' and 'betaPERT' distribution in such way that the mean and variance of betaPERT distribution are given by (Vose, 2000)

$$
\begin{gathered}
E(X)=\frac{a+\lambda m+b}{\lambda+2} \\
V(X)=\frac{(b-a)^{2}}{(\lambda+2)^{2}}
\end{gathered}
$$

The most common accepted value of $\lambda$ is 4 , so that the mean and variances are

$$
\begin{gathered}
E(X)=\frac{a+4 m+b}{6} \\
V(X)=\frac{(b-a)^{2}}{36}
\end{gathered}
$$

Using beta-PERT distribution with the three parameters minimum value (a), most likely value $(\mathrm{m})$ and maximum value (b) is similar in statistical aspects to triangular distribution which also takes three parameters. Following diagram illustrate how triangular distribution and beta-PERT distribution describe some hypothetical data-

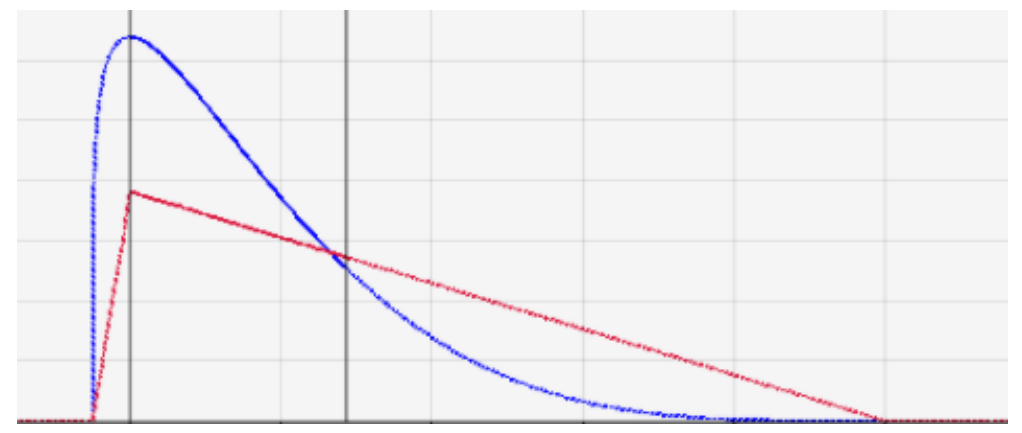

From above diagram we observe that the triangular distribution tends to provide lessjustifiable preference towards the skewed side. Moreover, the expected value given by triangular distribution is simple average of minimum value, most likely value and maximum value whereas, that given by beta-PERT distribution is weighted average of minimum value, most likely value and maximum value. As such, estimates based on beta-PERT distribution are more reliable than that based on triangular distribution. Data and information required for the preparation of this article are collected from "Shiva Shree Hydropower Limited". The company has already completed "Upper Chaku-A Hydropower Project" with capacity of $22.2 \mathrm{MW}$. It is now working on another project "Upper Balephi-A Hydropower Project" with a capacity of $36 \mathrm{MW}$. For generation of data required the master schedule chart of 'Upper Balephi-A' project was used. On the basis on this chart and by frequent discussion with executives and managers, II different project activities were identified. These activities are coded as A, B, C, DI, D2, D3, D4, E, F, G and H. The coded project activities are given below:
A. Pre-Construction Works
C. Tendering and Contract Awarding
B. Access Road Construction
DI. Pre-Construction 
Estimating Nep. J. Stat, Vol. 5, 2021

D2. Headwork Construction

D3. Water-way Construction

D4. Powerhouse Construction)

E. Hydromechanical works
Beta distribution for risk associated time schedule

F. Electromechanical works

G. Transmission line

H. Testing and Commisioning.

Though, the master schedule chart provides information about proposed start-date and completion-date of each activity. It is informed that these dates are fixed after discussion with the experts by simple rule of thumbs in a deterministic manner. Since it is intended to carry simulation of project schedule, some mathematical model that circumscribes different risk factors associated with project schedules is to be described. In the most common method of simulation called MonteCarlo simulation, three estimates of time involved with different project activities are considered. These three time estimates are:

a. minimum value - the time within which an activity will be completed if all external and internal conditions prevailing project work are favorable. It, in fact, represents optimistic value of time required to complete a task if there is no or moderate risk associated with different events. It is denoted as 'a'

b. maximum value, the time within which an activity will be complete if influencing factors are most highly unfavorable. It represents the pessimistic value of time required to complete the task if there is high associated risk. It is denoted as ' $b$ '

c. most likely time, the most realistic time estimate to complete the activity. It represents time of activities if risk is neither too high nor too low. It is denoted as ' $m$ '.

By formal discussion with project leaders data on minimum time, maximum time and most likely time of different activities were obtained. These times, in months, are stored in a data-frame and is presented below.

Table I. Data for time (in months) of completion of each activity in terms of unfavorable condition, most likely and favorable condition.

\begin{tabular}{lccc}
\hline Activity code & Minimum time & Most likely time & Maximum time \\
\hline A & 17 & 24 & 28 \\
\hline B & 20 & 24 & 30 \\
\hline C & 10 & 16 & 18 \\
\hline DI & 18 & 24 & 28 \\
\hline D2 & 20 & 26 & 27 \\
\hline D3 & 20 & 26 & 31 \\
\hline D4 & 22 & 26 & 30 \\
\hline E & 20 & 24 & 29 \\
\hline F & 18 & 24 & 28 \\
\hline G & 22 & 30 & 36 \\
\hline H & 1 & 1 & 1 \\
\hline
\end{tabular}


The estimated time of completion of different activities along with their variance estimated by using beta-PERT distribution are shown in Table 2 below. For a true simulation process randomness and repetition under identical condition are essnetial. For this purpose, a large number of random numbers of betaPert distribution is generated to simulate time of different activities related to hydropower project. The random numbers that are necessary for simulation purpose are generated using R-Studio (Team, 2020). The base platform of R consists of function of name 'rbeta()' to generate random numbers of standard beta distribution. This function takes three values as parameters: (a) ' $n$ ', the number of random values to be generated, (b) 'shapel', the vlaue of $\alpha$ and (c) 'shape2', the value of $\beta$.The base platform of $\mathrm{R}$ does not have any functionality to generate random numbers of betaPERT distribution. Though some external add-ins and packages are available to generate them directly in $\mathrm{R}$, in this paper a special user-defined function of name 'rb-to-rpert' is created. The function takes four values (i) ' $a$ ', the minimum time of completion of project activities, (ii) $\mathrm{m}$, the most likely time and (iii) ' $b$ ', the maximum time as parameters and (iv) ' $n$ ', the number of random values to be generated and it is fixed at 10000 to simulate the activity a large number of time. The function converts them to the parameters $\alpha$ and $\beta$ which are then used to call original 'rbeta()' function. If $\mu$ is the expected time of an activity obtained by using equation

$$
\mu=\frac{a+4 m+b}{6}
$$

then the relation between $a, m, b$, the parameters of betaPERT distribution, with parameters $\alpha$ and $\beta$ of standard beta distribution established as follows: (Davi, 2008)

$$
\begin{gathered}
\alpha=\frac{(\mu-a)(2 m-a-b)}{(m-\mu)(b-a)} \\
\beta=\alpha \cdot \frac{b-\mu}{\mu-a}
\end{gathered}
$$

The R-script code for function developed to implement above relationship is given below:

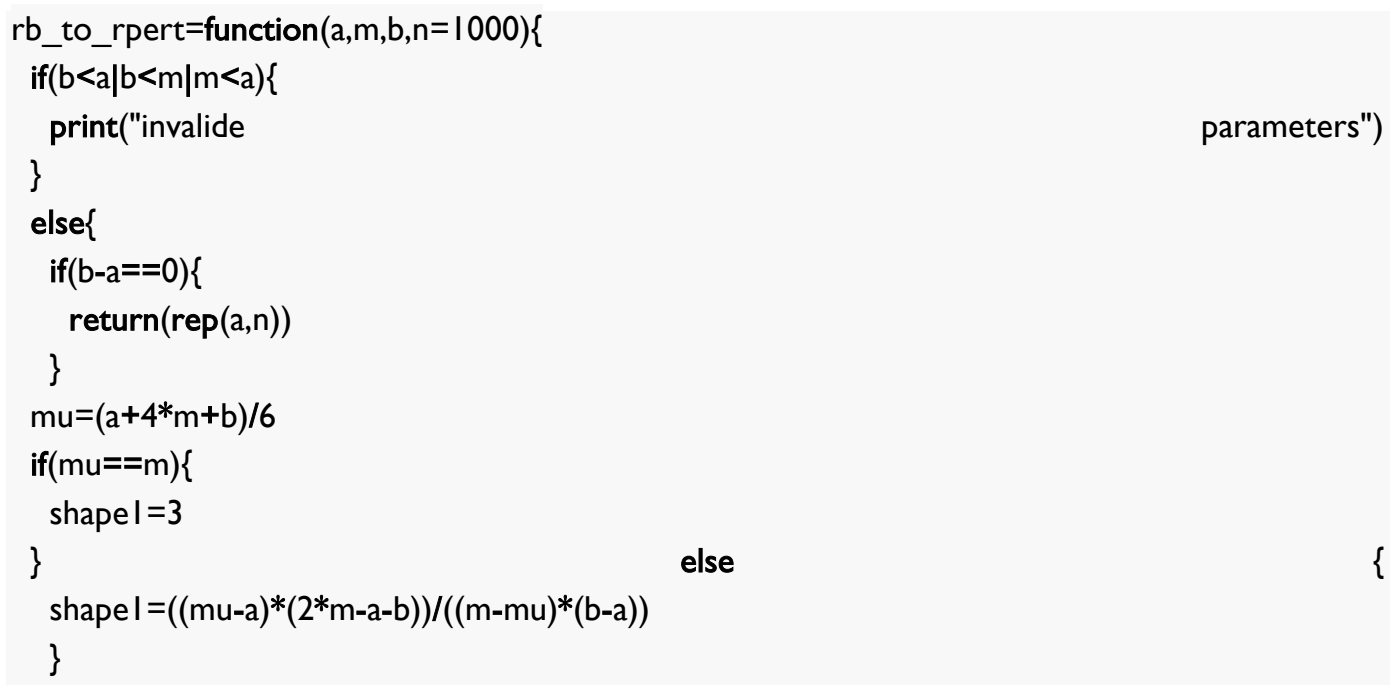




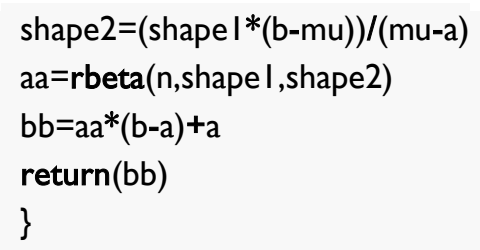

\section{RESULTS}

Using the data obtained on minimum time, most likely time and maximum time, following values of average time of different project activities with corresponding variances were obtained implementing traditional application of betaPERT distribution:

Table 2. Simulated values of time (in months) of different project activities by traditional way of using beta-PERT distribution.

\begin{tabular}{|c|c|c|c|c|c|}
\hline $\begin{array}{l}\text { Activity } \\
\text { codes }\end{array}$ & $\begin{array}{l}\text { Minimum } \\
\text { time }\end{array}$ & $\begin{array}{l}\text { Most likely } \\
\text { time }\end{array}$ & $\begin{array}{l}\text { Maximum } \\
\text { time }\end{array}$ & $\begin{array}{l}\text { Expected } \\
\text { time }\end{array}$ & Variance \\
\hline A & 17 & 24 & 28 & 23.50000 & $3.36 \mathrm{IIII}$ \\
\hline$B$ & 20 & 24 & 30 & 24.33333 & 2.777778 \\
\hline C & 10 & 16 & 18 & 15.33333 & 1.777778 \\
\hline DI & 18 & 24 & 28 & 23.66667 & 2.777778 \\
\hline $\mathrm{D} 2$ & 20 & 26 & 27 & 25.16667 & $1.361 \mathrm{III}$ \\
\hline D3 & 20 & 26 & 31 & 25.83333 & $3.36 \mathrm{IIII}$ \\
\hline D4 & 22 & 26 & 30 & 26.00000 & 1.777778 \\
\hline $\mathrm{E}$ & 20 & 24 & 29 & 24.16667 & 2.250000 \\
\hline $\mathrm{F}$ & 18 & 24 & 28 & 23.66667 & 2.777778 \\
\hline G & 22 & 30 & 36 & 29.66667 & 5.444444 \\
\hline $\mathrm{H}$ & 1 & $\mathrm{~T}$ & $T$ & 1.00000 & 0.000000 \\
\hline
\end{tabular}

These mean and variance values are applied extensively by project managers to identify the critical path that is used to estimate total project duration and also to evaluate performance of project activities. This traditional approach, however, does not include risk that is associated with different activities of the project. So, the measurements and estimates made on these values are less reliable. It is due to this reason, in this article attempts have been made to encapsulate more proportion of risks involved in project activities by implementing a function using $\mathrm{R}$-script to simulate project activities a large number of times. Using the function code, the real simulation of different project acitivities is carried by calling it for each and every activity listed in data-frame of different activities listed above (in Table I). It is to be noted that simulation process is carried 10000 times for function call on all activities one-by-one. The means and variance of simulated time of completion of each activity is computed and are presented below: 
Table 3. Risk associated means and variances of project activities estimated by simulation.

\begin{tabular}{lll}
\hline Activity code & Mean/months & Variance/months \\
\hline A & 23.49102 & 4.148734 \\
\hline B & 24.30509 & 3.456486 \\
\hline C & $15.3509 I$ & 1.976756 \\
\hline DI & 23.67404 & 3.442247 \\
\hline D2 & 25.16529 & 1.348623 \\
\hline D3 & 25.80766 & 4.235609 \\
\hline D4 & 25.98592 & 2.261159 \\
\hline E & 24.15311 & 2.916539 \\
\hline F & 23.66515 & 3.505251 \\
\hline G & 29.72255 & 6.769234 \\
\hline H & 1.00000 & 0.000000 \\
\hline
\end{tabular}

The major implication of values obtained in Table-3 above with respect to values in Table2 is the increased amount of variance in most of the project activity times. The increase in variances of project activity times is due to inclusion of schedule risks associated with them. The estimates of total duration of entire project as well as performance evaluation of project based on these values of mean and variance can be considered to be more realistic in comparison to those obtained from traditional method.

\section{DISCUSSION}

An interpretation of how the estimates of means and variances obtained by simulation for different project activities obtained in Table-3 cover risk factors we can observe histograms. The histograms of time of different project activities simulated for 10000 times are presented below:

Simulated Time

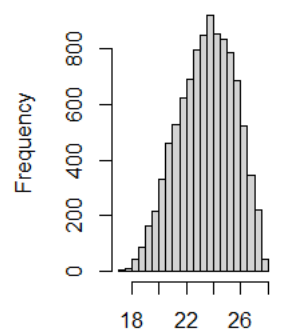

Activity A

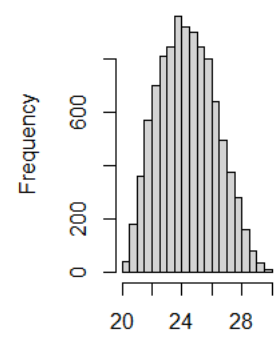

Activity B
Simulated Time

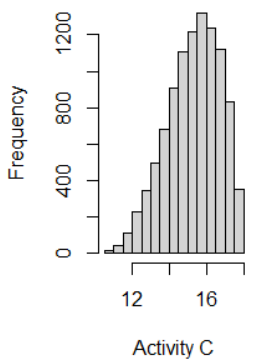

Simulated Time

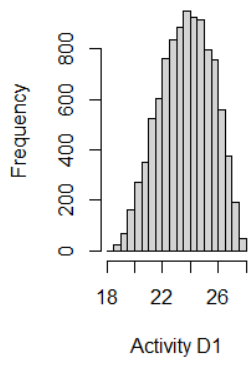



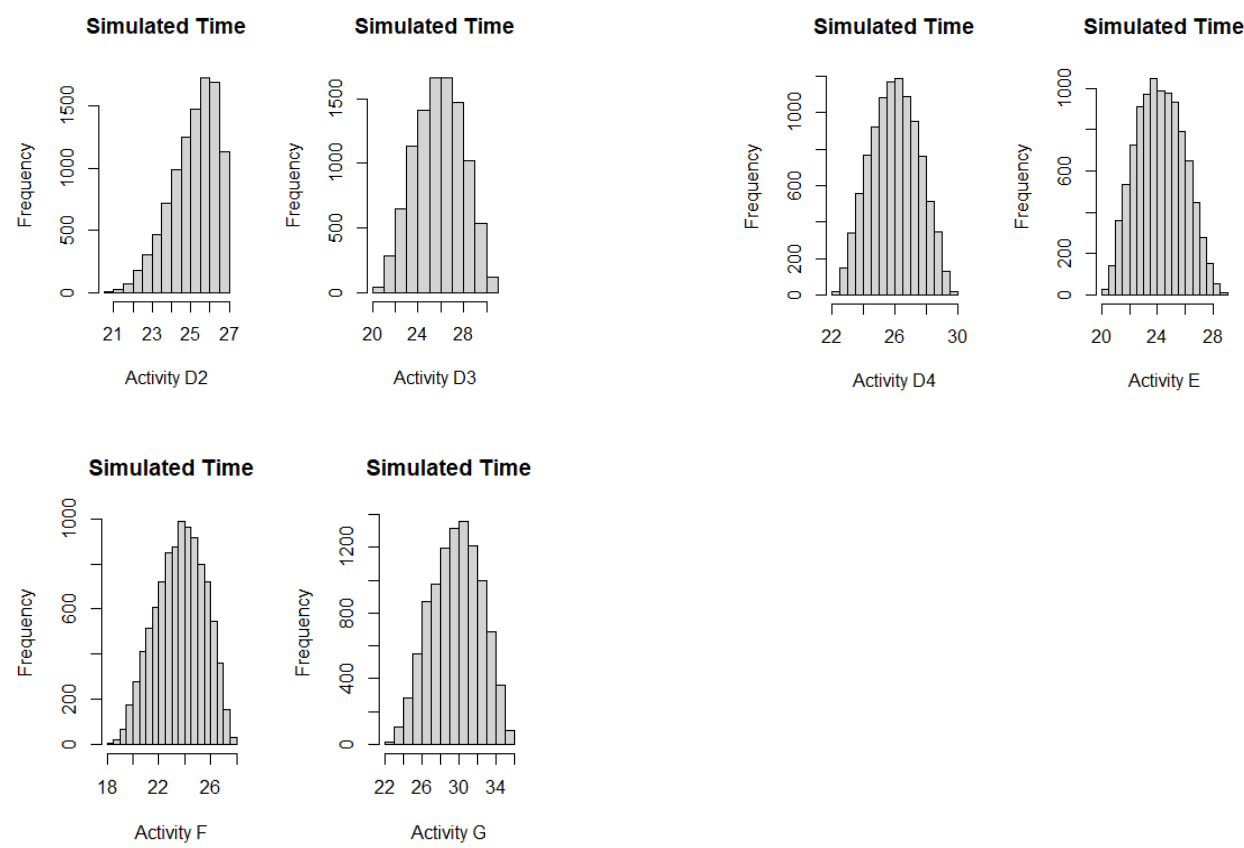

In above diagrams, the histogram for last activity is not mentioned since it is of very short duration and there is no variance in values. It is a well-accepted concept in Statistics that repeating a trial concerned with any distribution a large number of times can be modeled approximately by normal distribution. For demonstration, here mean and variance of first two activities shown in Table-2 are used to simulate normal distribution for 10000 times and histogram of result are shown below (for first two activities only):
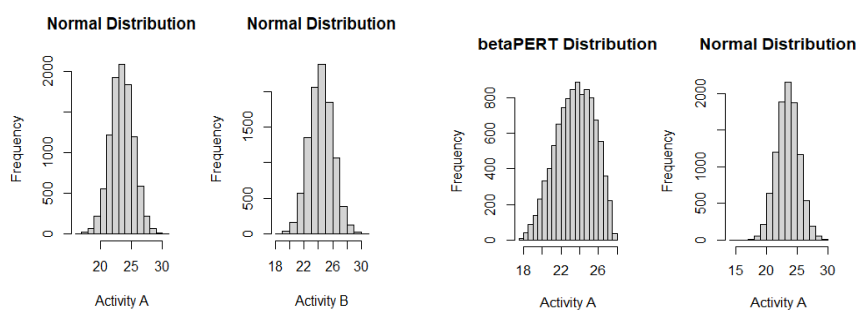

For comparison purpose, the histograms for 'Activity $A$ ' obtained by simulation of betaPERT distribution and by normal distribution are presented below side-by-side. From above two plots (for activity $A$ only) it can be revealed that normal distribution considers large part of values in middle portion and ignores extreme values in considerable high amount, but betaPERT distribution considers sufficient portion of extreme values. This is revealed from the fact that the tail part in histogram of betaPERT distribution are heavier in comparison to those of normal distribution. So the estimates of project time activities based on betaPERT distribution give more accurate results 
in comparison to other distributions. Moreover, since in this research simulation of beta distribution is implemented to associate risk factors in different project activities, so more realistic result on project activities times can be expected.

\section{CONCLUSION}

In this paper different activities involved in construction of hydropower project are identified. By simulation of data on optimistic time, pessimistic time and most likely time, the schedules of different activities with due consideration of associated risk factors is carried to obtain mean and variance of schedule time different activities of hydropower project. By proper consideration of the risks in hydropower construction project can result successful completion of the projects with respect to time, cost and quality. With due consideration of risk factors on time schedule of different project activities, the time of completion of entire project can be estimated with high degree of precision. There are many negative consequences that may result due to delay in project completion. So every project activity needs to carry risk analysis for project time estimation. In a similar manner risk analysis for project cost can also be carried for successful completion of projects.

\section{CONFLICT OF INTEREST}

The authors declare that they have no conflict of interest.

\section{ACKNOWLEDGEMENTS}

Gratitude is acknowledged, for providing responses to the questionnaire, participation in discussions and providing master schedule chart of the project to: (I) Umesh Kasaju: CEO, Shiva Shree Hydropower Limited, Anamnagar, Kathmandu (2) Rajan Pudasaini: Project Manager, Upper Balephi-A Hydropower Project

\section{REFERENCES}

Crawford, J. K. (20।4). Organizational Change Management: The New Mainstream. PM Solution Research.

Davi, R. (2008). Teaching Project Simulation in Exce/ Using PERT-Beta Distributions. INFORMS Transactions on Education.

Davis, R. (2006). Stochastic project duration analysis using PERT-beta distributions. San José State University.

Firoj Alam, Q. A. (2017). A review of hydropower projects in Nepal. Energy Procedia.

Flyvbjerg, B. \&. (20/8). Do classics exist in megaproject management?. International Journal of Project Management. 36(2018). 334-24I.

doi:http://dx.doi.org/10.1016/j.ijproman.2017.07.006

Gurung, S. (2020). Risk analysis for the sustainable hydropower development in Nepal. International Journal of Advanced Engineering, Sciences and Applications, I(2), I-5. Ismaili, N. (1995). The Standish Group Report. Academia. 
Kolk, A., Kourula, A., Pisani, N., \& Westermann-Behaylo, M. (2019). The state of international business, corporate social responsibility, and development: Key insights and an application to practice. Business and Development Studies. Routledge.

Panthi, K. (2007). Himalayan Research Papers Archive. Prioritizing and estimating hydropower project construction risks: a case study of Nyadi Hydropower Project.

Shrestha, R. S. (2018). A power paradox: Growth of the hydro sector in Nepal. Hydro Nepal: Journal of Water, Energy and Environment, 23, 5-2I. doi: https://doi.org//0.3126/hn.v23i0.2082।

Tripathi, P., \& Shrestha, S. K. (2017). Risk assessment of Boot hydropower projects in Nepal using fuzzy logic approach. Journal of Advanced College of Engineering and Management., 3, II5-125. doi:https://doi.org/I0.3126/jacem.v3i0.18965

Team, R. (2020). RStudio: Integrated Development Environment for R. Boston, MA.

Voetsch, R. J. (2004). Project Risk Management Practices and their association with Reported Project Success. IRNOP VI Project Research Conference. The International Research Network on Organizing by Projects.

Vose, D. (2000). Risk Analysis - A Quantitative Guide. John Wiley \& Sons.

Reference to this paper should be made as follows:

Shrestha, K. K. \& Kayastha, R. (202I). Beta distribution for estimating risk associated time schedule of hydropower projects in Nepal. Nep. J. Stat, 5, 67-78. 